\title{
STEAM Approach for Architecture Education
}

\author{
Arzu Gönenç Sorguç ${ }^{1}$, Çă̆lar Fırat Özgenel ${ }^{2}$, \\ Müge Kruşa Yemişcioğlu ${ }^{3}$, Fatih Küçüksubaşı ${ }^{4}$, \\ Soner Ylldırım ${ }^{5}$, Ernesto Antonini ${ }^{6}$, Luigi Bartolomei ${ }^{7}$, \\ Nis Ovesen $^{8}$, Nicolai Steinø ${ }^{9}$ \\ 1,2,3,4,5 Middle East Technical University ${ }^{6,7}$ University of Bologna ${ }^{8,9}$ Aalborg Uni- \\ versity \\ 1,2,3,5 \{arzug|fozgenel|mugek|soner\}@metu.edu.tr \\ 4fatihksubasi@gmail.com6rernesto.antonini@unibo.it ${ }^{7}$ luigi.bartolomei@unibo.it \\ 8nove@create. \\ aau.dk9steino@create.aau.dk
}

Starting with the first founded university, higher education has been evolving continuously, yet the pace of this evolution is not as fast as the changes that we observe in practice. Today, this discrepancy is not only limited to the content of the curricula but also the expected skills and competencies. It is evident that 21st-century skills and competencies should be much different than the ones delivered in the 20th-century due to rapidly developing and spreading new design and information technologies. Each and every discipline has been in continuous search of the "right" way of formalization of education both content and skill wise. This paper focuses on architectural design education incorporating discussions on the role of STEAM (Science Technology, Engineering, Art and Mathematics). The study presents the outcomes of the ArchiSTEAM project, which is funded by EU Erasmus + Programme, with the aim of re-positioning STEAM in architectural design education by contemplating 21st-century skills (a.k.a. survival skills) of architects. Three educational modules together with the andragogic approaches, learning objectives, contents, learning/teaching activities and assessment methods determined with respect to the skill sets defined for 21st-century architects.

Keywords: STEAM, Architectural Education, Survival Skills

\section{INTRODUCTION}

In our day, requirements for the individuals are rapidly changing and evolving due to the liberation of information. Exponential increase of accessible data which triggers competences and knowledge to expire and become obsolete faster than ever before. In this sense, sustainable learning becomes a very crucial issue to cope with the demands of the 21 st-century, Industry 4.0 and beyond. Today, one of the most important goals is to transform existing 
economies to green economies. One of the prominent features of green economy is high dependency on the level of education. Hence, how education should be re-structured and enable learners to have new mindsets and furnish them with green and digital skills is a crucial issue for individuals to be a part of sustainable economy. These skills differ from traditional schools' outcomes in terms of not only being content-based knowledge. Correspondingly, critical thinking, creativity, communication, and collaboration have been proposed as the "Four C's of 21stcentury learning" by the United States Based Partnership for 21 st-century skills which is a non-profit organization founded in 2002 [7].

Educational research studies are looking for ways to enhance students' learning and equip students with skills that are helpful to meet the 21 st-century's demands (Retna, 2015). Easy access of information and high availability of technology makes our lives easier; yet, the definition of being a successful student and significant factors that are necessary for being successful both in academic and professional life has also changed. Architectural education is not an exception in this sense.

Architects of the past, or today or the ones in future should be able to incorporate and conduct a large amount of knowledge and data as well as to be able to cope with changes related with technology, culture, sociology, economy and more. They are expected to be creative and innovative in order to compete and to survive in the world of change. STEAM (Science, Technology, Engineering, liberal Arts and Mathematics) which is a holistic educational perspective of all these fields is a very promising structure in architectural education. The idea of STEAM actually exists almost in every curriculum of schools of architecture implicitly at varying levels of integrity. Yet, revisiting the contemporary curricula of architecture schools from the principles of STEAM approach provides an opportunity to revise the skill sets and learning outcomes of the education with respect to the everlasting demands of the time in a more flexible structure.
In this regard, ArchiSTEAM Project, which is an EU-funded Erasmus+ Project, is conducted with the collaboration of Middle East Technical University (METU), University of Bologna (UNIBO) and Aalborg University (AAU) to analyze the architectural education and the relevance of STEAM approach, and to develop teaching/learning modules to enable the integration of STEAM mindset to the existing curricula of architecture schools.

\section{STEAM APPROACH IN ARCHITECTURE ED- UCATION: ARCHISTEAM APPROACH}

Education technologists and academics try to improve their students' 21 st-century skills by using different learning approaches. Science, Technology, Engineering, Math, Art (STEAM) education is one praxis of efforts. STEAM education contains skills, knowledge, and beliefs that are collaboratively constructed at the intersection of more than one STEAM subject area (Corlu et al. 2014). The STEAM approach in teaching aims to prepare individuals with high creative and innovative skills and to improve learning outcomes and prepare students to the era that we live in. In this respect, the STEAM approach offers more than the sum of all parts (disciplines) and focuses on how to blend these disciplines in harmony for further understanding. Correspondingly, The STEAM approach fundamentally deals with the modes of conveying the skills and knowledge rather than combining the subjects in focus. Moreover, STEAM provides a teaching frame for instructors from different fields to create a progressive learning environment for students. It is a catalyst for students to combine their science and art skills to provide innovative solutions to challenging problems of the real world.

STEAM experiences involve two or more standards from Science, Technology, Engineering, Math and the Arts to be taught and evaluated through each other. On the other hand, students' understanding of how things work can be increased, and their use of technologies can be developed by a true STE(A)M education (Bybee, 2010). STEAM approach 
centralizes on inquiry, collaboration, and an emphasis on process-based learning aiming for exploring new and creative ways of problem-solving, displaying data, innovation, and linking multiple fields. STEAM provides more real-life connections to students and teachers, and through a powerful combination of topics and techniques for educating our society is aroused.

It is a long and controversial debate "how design education should be" and "what is designerly way of thinking". In all these discussions, what is consented is "design is one of the most advanced thinking skills" for which constructivist learning becomes the core. Constructivist learning is the way for the mind to transform data into knowledge based on experience. Dewey (as cited in Bhattacharjee, 2015) argued that human thought is practical problem solving, which proceeds by testing opposing hypotheses. These problem-solving experiences occur in a social context, such as a classroom, where students join together in manipulating materials and observing outcomes. (Dewey, as cited in Bhattacharjee, 2015) Since it is relying on a student-centered approach, students are encouraged to use active techniques (experiments, real-world problem solving) to construct knowledge. By designing and performing a number of teaching practices for a well-planned learning environment, the students learn how to acquire knowledge and learn.

It should be highlighted that constructivism is not a teaching model, but it is a frame of thought; an ideology based on three main learning strategies: experiential learning, problem-based learning and project-based learning for which learners are actively engaged, i.e. it is learner-centered. When design education in the focus of studios is considered either project-based or problem based, experiences will serve in developing such a constructivist mindset. In this process, the role of the instructor/mentor is crucial.

Unlike traditional approaches, constructivism modifies the role of the teacher by changing from active to guiding role for helping the student to construct knowledge. Constructivism requires active participation of students in the learning process rather than being a passive recipient of information as well as the guidance of teachers to construct students' knowledge instead of causing mechanical ingestion of knowledge by them.

In this process, it is evident that each individual has a different learning style. Kolb and Fry (1974) say that "knowledge results from the combination of grasping experience and transforming it." Accordingly, in this learning process, four main phases namely; experience, reflection, conceptualization, and experimentation take place. Successful experiential learning requires that each stage being mutually supportive of and feeding into the next. Hence controlling the learning process, properly designing the "learning environment" by the instructor/mentor starting from the assignment of the problem to the assessment, objectives, and outcomes become the key issues as well as the skill sets to be conveyed during the education and thereafter. Hence, revisiting design education with this perspective will help to restructure design education regarding skill sets that are expected from the graduates of architecture schools. For this purpose, firstly the framework for developing modules are constructed which is then implemented to architecture education within the scope of the ArchiSTEAM project.

\section{MODULE DEVELOPMENT}

Teaching modules are usually conceptualized as selfcontained "units" of content. Multiple modules constitute an instructional course or training program. A unit can cover just one class or more. Likewise, a course may contain a variety of modules whereas a module teaches a complete skill or a meaningful content. It usually covers just one subject and is assessed independently of other modules in order to enable flexible/adaptable course design. According to Yelon (1996), Teaching modules are composed of 4 main components. Those are (1) Instructional objectives/Objectives, (2) Content, (3) Teaching/Learning Activities, (4) Evaluation. 


\begin{tabular}{|c|c|c|c|}
\hline Instructional Objectives & Content & $\begin{array}{l}\text { Teaching/Learning } \\
\text { Activities }\end{array}$ & Assessment \\
\hline $\begin{array}{l}\text { State your instructional } \\
\text { objectives in SMART format }\end{array}$ & $\begin{array}{l}\text { List Facts, Concepts, } \\
\text { Principles and Skills related } \\
\text { to the instructional } \\
\text { objectives }\end{array}$ & $\begin{array}{l}\text { Define the teaching activities } \\
\text { (presentation, group } \\
\text { discussion, project based } \\
\text { learning, demonstration) }\end{array}$ & $\begin{array}{l}\text { Define on the measurement } \\
\text { type in accordance with } \\
\text { learning objectives (Rating } \\
\text { Scales and/or Checklist) }\end{array}$ \\
\hline
\end{tabular}

\begin{tabular}{lllll}
\hline & Facts & Concepts & Principles & Skills \\
\hline Ideas & Organized set of facts & $\begin{array}{l}\text { Definition of the } \\
\text { category }\end{array}$ & $\begin{array}{l}\text { Definitions relating } \\
\text { variables }\end{array}$ & $\begin{array}{l}\text { Ordered simplified } \\
\text { steps }\end{array}$ \\
Examples & $\begin{array}{l}\text { Vypical example-non } \\
\text { Substantiation }\end{array}$ & $\begin{array}{l}\text { Evidence showing } \\
\text { relationship between } \\
\text { example pair }\end{array}$ & Demonstration \\
& & & \\
& & &
\end{tabular}

Table 1

Components of a Teaching Module [3]

\section{Table 2}

Sub-categories of Module Content [3]

\section{Instructional Objectives}

Instructional objectives can be viewed as outcomes of the instruction. In other words, instructional objectives are the description of the knowledge and skills that we want students to gain during the instruction. Although there are several approaches for writing effective instructional objectives, S.M.A.R.T. method (Doran, 1981) is chosen within the scope of ArchiSTEAM project. S.M.A.R.T. The acronym stands for:

1. Specific: Make sure that objectives make the same sense for all including students and instructors.

2. Measurable: Remember that unless you define observable outcomes, you cannot know whether learners gained the necessary knowledge and skill at the end of the instruction. Thus, the student's performance must be measurable by both quantitative and qualitative criteria.

3. Action-oriented: Make sure that you use action verbs in your objectives so that student's performance can be evaluated.

4. Realistic: Make sure that expectations from the students are realistic in terms of conditions and time given.

5. Time-Based: Make sure that students are given proper time to attain objectives.

\section{Content}

In his instructional design model, Yelon (1996) links content directly with the instructional objectives, methods, and assessment. It means instructors are required to teach students related content that will help them gain the necessary knowledge and skills to achieve learning outcomes and to perform successfully on the assessment. The content should be relevant, appropriate to the students' background and their learning styles and structured to provide a meaningful learning experience. Yelon (1996) refers to content as "essential content to teach" and claims that essential content has 4 sub-categories (or types of knowledge to be taught): (1) Facts (2) Concepts (3) Principles (4) Skills. The underlying assumption behind categorizing content under 4 themes is that each type of content requires different mental processes and efforts to be learned. These subcategories are defined and exemplified in Table 2.

\section{Teaching / Learning Activities}

Teaching/learning activities are related to the activities conducted to convey the desired instructional objectives to the learners. In their work, Joyce, Weil \& Calhoun (2008) categorized teaching methods under 4 main themes as Social Interaction Family emphasizing the relationship of the individual to society or to other persons. Gives priority to the indi- 
vidual's ability to relate to others, Information Processing Family emphasizing the information processing capability of students, Personal Family emphasizing the development of individuals, their emotional life and selfhood, and Behavioral Modification Family emphasizing the development of efficient systems for sequencing learning tasks and shaping behavior.

\section{Assessment}

Assessment is the most crucial component of an instructional model due to its nature. Assessment requires collecting systematic data about the students' progress in the learning environment. This data serves for several instructional purposes such as providing evidence about how instructional objectives are realistic or attainable by students, indicating the effectiveness of the teaching method assessment and providing evidence to make a judgment about the students' performance. Rating scales and checklist are some of the most frequently used assessment tools.

\section{ARCHISTEAM MODULES}

With the continuous development of technologies and accumulation of data, the expected knowledge and competencies are expiring rapidly, affecting every profession including architecture. In this respect, the STEAM modules in architecture (ArchiSTEAM modules) are focused on the generic skills relevant to architecture which will provide learners necessary tools to cope with the changing demands of the field and professional life. Correspondingly, the modularity and flexibility of the modules became prominent features of the developed modules. The primary objectives of ArchiSTEAM modules can be expressed as follows:

- The modules should be skill based instead of knowledge based in order to be adaptable to changing requirements of the era

- The teaching/learning activities should foster creativity

- The modules should create self-awareness and self-motivation for life-long learning
- The modules should foster professional soft skills

- The skills of the modules should be relevant to architectural education yet be generic to enable implementation in any course within the curricula

- The modules should be flexible in terms of conduction time and serve for varying durations of teaching activities such as workshops, courses or entire curricula

- The modules should be consistent in themselves to enable standalone implementation

After conducting several surveys with instructors, students and professionals, and in-depth analysis of the curricula of three partnering universities representing different ecoles, the relevant and missing skills are determined. The detailed information of these surveys is present in 1st and 2nd project reports [1,2]. Correspondingly, the determined skills are grouped under three categories in order to develop coherent and consistent modules. These three skill sets are namely Ground (Baseline) Skills, Problem Based Learning Skills (PBL) and Information and Communication Technologies (ICT) Skills. Ground (baseline) skills are to facilitate adaptation/survival of individuals independent of their discipline, age or background. In general, these skills address challenges in professional life in terms of communication and collaboration with close connection with skills required to architecture profession. PBL Skills, on the other hand, enhance problem-solving abilities through experiential learning. It promotes solution oriented analytical thinking and decision making. Finally, another complementary skill set addressing ICT is proposed to enrich the capability of students not only to use rapidly developing information technologies but also to prompt to develop and challenge the technological development. These skill sets are actualized in three education modules together with the instructional objectives/objectives, module content, teaching/learning activities, and assessment methods. Each skill sets are also subdivided into several groups with respect to the shared content and teach- 

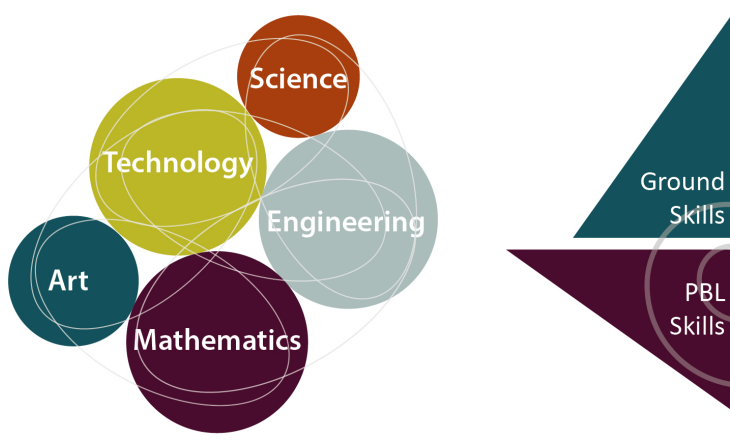

ArchiSTEAM Modules

The number of Learning Outcomes/Skills determined

G-Ground Skills

G-A Design Process

20

6

G-B technical skills related to the control of structural and technological components

G-C Ground Skills

PBL- Problem Based Learning Skills

PBL-A General University Skills

PBL-B PBL-related skills

PBL-C Architecture and design-related skills

Information Communication Technologies Related Skills

ICT-A Information Retrieval

ICT-B Data Usage

ICT-C Collaboration

ICT-D Self Sustainability

ICT-E Troubleshoot
Figure 1

Intertwined nature

of the STEAM

approach and the

ArchiSTEAM

modules

Table 3

The ArchiSTEAM

modules and the

corresponding

number of Learning

Outcomes/Skills 
ing/learning activities.

It should also be noted that the skills and corresponding learning objectives were determined and formulized in such a way that they form a meaningful whole as well as being adaptable to any course. In this respect, these learning objectives do not aim to deliver a particular course content or knowledge but aim to foster the understanding of the learner for any course in architectural education. Yet, as the module definition brings the necessity of being selfcontained units, the three ArchiSTEAM modules constitute overlapping learning objectives, e.g. "as being able to conduct in-depth research" with nuances in how they are put into words in PCL and ICT modules. The intertwined nature of ArchiSTEAM modules and the STEAM approach are illustrated in Figure 1. As a result, a total of 97 skills are determined, and the number of kills per module is shown in Table 3.

ArchiSTEAM modules are developed to be adaptable to any teaching practice, regardless of its duration and subject matter. Hence, they are usable in a variety of cases from a short workshop to the whole curriculum. In addition, these modules are constructed to form a basis for further development. Undoubtedly, the requirements of the next 20 years will be different from today's, and these modules should be renewed continuously in coherence with the objectives of education and in pace with current technologies. Education technologies and methodologies are also subjected to be revised/modified/altered in time. In this regard, any skill set such as provided here should be revised whenever necessary. The framework presented herein should be perceived as a guide reflecting contemporary needs and approaches. Moreover, it exemplifies the general rules of thumbs and principles of content and module design from a broader perspective. Hence, the schema presented within the scope of this project acts as a guideline and typical application of how to develop a framework for the aforementioned goals.

\section{CASE STUDIES AND REFLECTIONS}

The three STEAM modules proposed within the scope of the project are tested in two ways as; implementation in three different courses (Digital Design Studio, METU; Lab-based Course on Building and Architecture, UNIBO; Urban Technologies Course, AAU) at each partnering institutions [4] and testing through workshops organized in three different countries [5]. For the course implementations, the existing course syllabi are modified with respect to the ArchiSTEAM modules, and the maximum number of ArchiSTEAM skills are aimed to be implemented in coherence with the content of the courses to be implemented. For testing purposes, pre and post surveys are conducted with the students in order to trace the effect of integrating STEAM skills to the existing courses. Similarly, in order to test the flexibility of the modules in the time domain, three short workshops ( 1 - 3 days) are conducted in three partnering institutions in order to avoid cultural bias. Similar pre and post surveys are conducted with the workshop participants. The adaptation of ArchiSTEAM modules into education are found to be beneficial in terms of enhancing the understanding of the learners and delivering survival skills regardless of the duration of the training, cultural background, gender, age or educational background of the learners. Following reflections are documented with respect to the feedback from the learners and instructors who experience the integration of ArchiSTEAM modules:

- Assigning an open and ill-defined problems force students out of their comfort zone and broaden the understanding of the students by requiring them to confront with multiple disciplines, which positively influences both the design process and the final product.

- Multidisciplinary and problem-oriented approach motivates the students. Students are inspired by the implementations in other disciplines. Students are encouraged to come up with innovative ideas pushing their own limits. 
- Cross-disciplinarity among the teaching staff forces instructors to engage mutually with each other's professional fields. Potential inter-relatedness of the discipline reflects the students' collaboration habits and being able to approach problems on a broader perspective

- ArchiSTEAM approach is beneficial for establishing high student motivation. This approach also enables high learning outcome, self-motivation of students, and crossdisciplinary approach to problem-solving. This is beneficial for both students and teachers, and it likely represents a strong and powerful trajectory in course development in higher education.

- The assessment process and means of assessments are crucial in the learning process in regard to setting the proper PBL environment and supporting the learning process of students.

- The STEAM approach as a way of structured integration of various disciplines invokes learning experience and furnishes creativity.

- ArchiSTEAM modules foster self-awareness of the students in terms of skills they acquire which promotes motivation to determine, revisit and renew expiring skills.

- The role of instructors which is practiced as mentors in the groups was very crucial. It was seen that students could effectively work in groups and be productive as long as mentors facilitate the design process by supporting them with proper assessments and coaching techniques

The knowledge and experience acquired throughout the project lifetime are compiled with a user-friendly interface to provide a guideline for the instructors who aim to follow a similar route to utilize the STEAM approach in their courses and education programs. This guideline is shared through the project website and is visualized in Figure 2.

\section{CONCLUSION}

The ArchiSTEAM Project was a two-year project aiming to provide the ground to establish a STEAM approach in architectural design education. The STEAM approach is considered as an enabler for architecture students to work in an interdisciplinary way, and to approach design problems in a broadened perspective in their profession. It is also strongly advocated that the STEAM approach brings innovation and creativity into the design process.

It is evident that architectural education and especially design education has always been a controversial issue and each school has its own way of structuring their curriculum, and yet what is most common is the implicit implementation of STEAM. It is believed that the analysis of current curricula and revisiting the learning outcomes/objectives with respect to the STEAM approach and sustainability perspective will provide the opportunity to reshape architectural education to prepare students for the era which requires the ability to adapt to changing needs rapidly.

In the field of architecture, three skill sets ground skills, PBL skills, and ICT skills - on top of the professional skills that are gained during education are essential for students, not only in their span of education but also in their professional life. These skills can be considered as green skills for the sustainability of their profession. In this sense, the STEAM approach is used as a guideline for determining the 21 st-century skills and the modes of conveying those skills to the students together with the outcomes / possible content / teaching activities and assessment methods. The STEAM approach also serves as a way of structured integration of various disciplines to invoke learning experience and furnish creativity.

As a result of this study, three flexible and adaptable teaching modules are developed as an exemplary implementation of STEAM in architecture with respect to the determined STEAM skill sets. These modules are suitable for integration to any course or training as well as permitting to a stand-alone application. It should be noted that also the learning out- 
Figure 2

WikiSTEAM

Guideline [6]

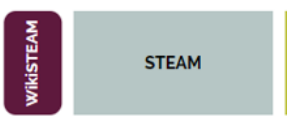

\section{Teaching / Learning Approach in ArchiSTEAM}

\section{ArchiSTEAM Skills}

How to Design a STEAM-based module?

Instructional Goals and Objectives Description How to develop Example as a course (104) Example as a workshop (O5) Related Reports External Links

Teaching/Learning Activities Partner and Group Collaboration Inductive Investigation \& Inquiry Deductive Investigation \& inquiny Synectics Techniques for Creativity Design and Problem Solving Proiects \& Reports Projects \& Reports
Awareness Training / Values Clarification Self-Reflaction Direct Instruction (Demonstrations Presentations:
Simulations

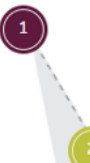

Content

(1) Facts

(2) Concepts

(4) Skills (Rofer to Skills presented before)

(3) (4) Skills. Refer to sh
Role of Assessment in the education

Pating Scales

Checklists Measurement of Complex Cognitive Outcomes Performance Based Assessment
WELCOME TO WIKISTEAM GUIDELINE

This interactive guideline is prepared with the purpose of presenting the core of the research outputs of ArchiSTEAM project which aims raising architects who are self-sufficient and able to develop sustainable and digital skills by means of integrating STEAM (Science. Technology. Engineering Arts and Mathematics) to the existing architecture curricula ArchiSTEAM project delivers 5 intellectual outputs which you may access by clicking the REPORTS button. Furthermore, in order to ease the accessibility to the knowledge produced. WikiSTEAM interactive guideline introduces core concepts of STEAM approach. expected skills and components of designing a STEAMbased teaching module. As you navigate in the interactive chart brief information regarding these components will be displayed together with the link to related chapters of the reports. If you have any questions or comments please send an e-mail to info@archisteam.com Enjoy 
comes/objectives are not definite and should be revised with the changing technologies and modes of learning in time. In this respect, the project aims to deliver a guideline for the andragogy of architectural education for sustainable learning and green skills for the 21 st century.

\section{ACKNOWLEDGEMENT}

This paper is supported by the Turkish National Agency and European Union's Erasmus+ Programme under grant agreement 2016-1-TR01-KA203-034962, project ArchiSTEAM (Greening the Skills of Architecture Students via STEAM Education) with the collaboration of Middle East Technical University, University of Bologna and Aalborg University

\section{REFERENCES}

Bhattacharjee, J 2015, 'Constructivist Approach to Learning- An Effective Approach of Teaching Learning' International Research Journal of Interdisciplinary \& Multidisciplinary Studies (IRJIMS), 1(6), pp. 65-74

Bybee, RW 2010, 'What Is STEM Education?', Science, 329(5995), p. 996

Corlu, M, Capraro, RM and Capraro, MM 2014, 'Introducing STEM education: Implications for educating our teachers in the age of innovation', Education and Science, 39(171), pp. 74-85

Doran, GT 1981, 'There's a S.M.A.R.T. Way to Write Management's Goals and Objectives', Management Review, 70(11), pp. 35-36

Joyce, BR, Weil, M and Calhoun, E 2008, Models of Teaching (8th Edition), Pearson

Kolb, DA and Fry, R 1974, 'Towards an Applied Theory of Experiential Learning', in Cooper, C (eds) 1974, Theories of Group Processes, John Wiley \& Sons

Retna, KS 2015, 'Thinking about "design thinking": a study of teacher experiences', Asia Pacific Journal of Education, 36(1), pp. 5-19

Yelon, SL 1996, Powerful Principles of Instruction, Longman Publishers, New York

[1] http://archisteam.com/wp-content/uploads/2018/0

1/O1_FINAL.pdf

[2] http://archisteam.com/wp-content/uploads/2018/1

1/o2report.pdf

[3] http://archisteam.com/wp-content/uploads/2018/1

1/o3report.pdf
[4] http://archisteam.com/wp-content/uploads/2018/1

1/o4report.pdf

[5] http://archisteam.com/wp-content/uploads/2018/1

1/o5report.pdf

[6] http://archisteam.com/digital-guideline/

[7] http://www.battelleforkids.org/networks/p21 